\title{
Safety and efficacy of EUS-guided pancreatic duct drainage in symptomatic main pancreatic duct obstruction: Is there still a place for surgery?
}

\section{(ㄷ)(1) $(-)$}

\author{
Authors \\ Arthur Falque, Mohamed Gasmi, Marc Barthet, Jean-Michel Gonzalez
}

Institution

Aix-Marseille Université, AP-HM, Hôpital Nord, Gastroenterologie, Marseille, France

submitted 24.4.2020

accepted after revision 7.10 .2020

\section{Bibliography}

Endosc Int Open 2021; 09: E934-E942

DOI 10.1055/a-1302-1484

ISSN 2364-3722

(c) 2021. The Author(s).

This is an open access article published by Thieme under the terms of the Creative Commons Attribution-NonDerivative-NonCommercial License, permitting copying and reproduction so long as the original work is given appropriate credit. Contents may not be used for commercial purposes, or adapted, remixed, transformed or built upon. (https://creativecommons.org/licenses/by-nc-nd/4.0/)

Georg Thieme Verlag KG, Rüdigerstraße 14,

70469 Stuttgart, Germany

Corresponding author

Dr. Arthur Falque, Hôpital Nord, Gastroenterology

Department, Chemin des Bourrely, Marseille, France

Fax: +0491941214

Arthur.falque@ap-hm.fr

\section{ABSTRACT}

Background and study aims In patients with symptomatic dilation of the main pancreatic duct (MPD) for whom endoscopic retrograde cholangiopancreatography (ERCP) is impossible, surgery has long been the only available treatment. EUS-PD is described as a minimally invasive alternative for ductal decompression surgery. We describe the results of our experience with it.

Patients and methods This was a retrospective singlecenter study over 9 years. Twenty-seven patients, median age 61.8 years (range 36 to 85 ) who underwent EUS-PD for symptomatic MPD dilatation were included. The main objective was to evaluate the technical success (placement of a plastic stent between the stomach and the MPD). Secondary objectives were to document clinical success based on pain and quality of life (visual analogic scales and treatments) and complication rates, and to define a standardized management algorithm.

Results The technical success rate was $92.5 \%$. The rate of minor adverse events was $21 \%$ (4 cases of non-specific postoperative pain and two cases of delayed benign edematous pancreatitis). The clinical success rate was $88 \%$, and half of patients in whom the procedure was successful had "complete regression" of pain and half "partial regression." Median follow-up was 34.2 months (range 4 to 108). During follow-up, $74 \%$ of patients reported improvement in quality of life and no patients required secondary surgery.

Conclusion Provided it is performed in an expert center, EUS-PD is a minimally invasive, effective, and safe alternative to pancreatic surgical drainage in patients with symptomatic MPD dilatation with failure or in whom ERCP is impossible.

\section{Introduction}

In the last decade, transgastric ultrasound-guided (EUS) pancreatic drainage has been promoted for complex alterations of the main pancreatic duct (MPD) that occur in cases of chronic pancreatitis (CP) and for the altered anatomy mainly associated with the Whipple procedure. The incidence of CP is 7.7/ 100,000 with a prevalence [1] of $26.4 / 100,000$, making the condition as prevalent as inflammatory bowel disease [2]. CP is defined as pancreatic disease in which recurrent inflammatory episodes lead to the replacement of pancreatic parenchyma by fibrous connective tissue, which gradually results in development of ductal and parenchymal abnormalities [3]. Pain is the main symptom, and leads to significant reduction in quality of life $[2,4]$. Its mechanism is complex, but likely linked to ductal hyper-pressure [3] induced by obstruction from intraductal calcifications and/or fibrous stenosis. In patient who have undergone surgery, this obstruction is secondary to pancreatic-jejunal or pancreatic-gastric surgical anastomosis stenosis. Pain management is well documented [5], and the drug therapy combined with endoscopy or invasive surgical typically is required to improve duct clearance and achieve pain regression. 
The endoscopic approach to MPD drainage was first described in the early 1980 s, and since 1987 , it has been widely used, with development of extracorporeal lithotripsy to fragment stones in CP. Endoscopic retrograde cholangiopancreatography (ERCP) is considered the first-line invasive treatment for symptomatic dilation of MPD [6-8]. Indeed, drainage with plastic stents allows for technical success rates of $90 \%$ to $97 \%$, with symptom regression in $60 \%$ to $80 \%$ of patients [9]. However, in $3 \%$ to $10 \%$ [10] of the cases, the drainage with ERCP is not feasible due to an impassable MPD stricture, obstructive lithiasis, duodenal stenosis, or altered anatomy post-surgery $[9,11-$ 13]. In these situations, surgery has been the only available treatment [14], with efficacy comparable to endoscopy [15] and clinical success rates ranging from $65 \%$ to $85 \%$. However, the adverse event (AE) and mortality rates can reach $30 \%$ and $2 \%$, respectively [16-18]. In addition, anastomotic stricture may occur after the procedure, causing painful obstruction of the upstream duct of Wirsung $[16,19,20]$.

Interventional ultrasound also has evolved considerably, with techniques such as transgastric ultrasound-guided drainage of pancreatic pseudo-cysts and walled-off necrosis, and more recently, hepatico-gastrostomy for transgastric biliary drainage [21,22]. Following this dynamic, the EUS-guided pancreatic duct drainage (EUS-PD) first was described by François et al. using a cystotome. Then, various techniques for creating the path between the pancreatic duct and the stomach were proposed with balloon dilation [23, 24], with an increased risk of pancreatic leakage, as indicated in the PRINCEPS study [12].

Despite several technical improvements, the technique remains technically complex. This has been reported in various studies, all retrospective and single-center with small sample size $[9,12,25-27]$. More recently, multicenter studies have been published, with larger numbers of patients $[11,28]$ and longer follow-up. The technical success rate is approximately $90 \%$, with clinical efficacy observed in $70 \%$ to $90 \%$ of patients, who have a significant reduction in pain.

Thus, we present our series, which evaluated the results of EUS-PD in management of symptomatic dilation of the MPD that has failed to respond to ERCP or in patients for whom that procedure is impossible. The objectives were to evaluate the safety and the efficacy of the procedure.

\section{Patients and methods}

\section{Study design and patients}

This was a single-center, retrospective study of consecutive cases, conducted at the North Hospital in Marseille, to evaluate EUS-PD of the MPD. All the patients in for whom MPD drainage was indicated because of symptomatic dilation were identified using a retrospective database that included information on all ERCP or therapeutic EUS procedures performed in our tertiary center between January 2010 and January 2019. This database meets national criteria for protection of patient data and is validated by the CNIL (Commission Nationale de I'Informatique et des Libertés).

All patients included the analysis were suffering painful pancreatic stenosis (CP or anastomotic stricture) associated
- Table 1 Patient characteristics and etiologies of MPD dilatation.

\begin{tabular}{|c|c|}
\hline Patients, n & 27 \\
\hline Average age, years [min-max] & $61.8[36-85]$ \\
\hline \multicolumn{2}{|l|}{ Sex, \% (n) } \\
\hline - Female & $29.6 \%-(8)$ \\
\hline - Male & $70.4 \%-(19)$ \\
\hline Tobacco, \% (n) & $40.7 \%(11)$ \\
\hline Alcohol, \% (n) & $29.6 \%(8)$ \\
\hline Average BMI, [min-max] & $22.4[16-37]$ \\
\hline \multicolumn{2}{|l|}{ Daily analgesic consumption ${ }^{1}, \%(n)$} \\
\hline - Levell & $96.2 \%(26)$ \\
\hline - Level II & $14.8 \%(4)$ \\
\hline - Level III & $18.5 \%(5)$ \\
\hline \multicolumn{2}{|l|}{ Pain, \% (n) } \\
\hline - Postprandial/continuous & $40 \%(11)$ \\
\hline - Acute pancreatic attacks & $60 \%(16)$ \\
\hline \multicolumn{2}{|l|}{ Etiology of MPD dilation } \\
\hline - Chronic pancreatitis (classification TIAR-O) & $66.6 \%(18)$ \\
\hline - Toxic - metabolic & $50 \%(9)$ \\
\hline - Obstructive & $16.6 \%(3)$ \\
\hline - Idiopathic & $33.3 \%(6)$ \\
\hline - Altered anatomy post CDP & $33.3 \%(9)$ \\
\hline - IPMN & $44.4 \%(4)$ \\
\hline - Cystic dystrophy & $11.1 \%(1)$ \\
\hline - Ampulloma & $22.2 \%(2)$ \\
\hline - Mucinous cystadenoma & $11.1 \%(1)$ \\
\hline . GIST & $11.2 \%(1)$ \\
\hline \multicolumn{2}{|c|}{$\begin{array}{l}\text { MPD, main pancreatic duct; CDP, cephalic duodenopancreatectomy; IPMN, } \\
\text { intraductal papillary mucinous neoplasm; GIST, gastrointestinal stromal } \\
\text { tumor. } \\
{ }^{1} \text { According to OMS classification }\end{array}$} \\
\hline
\end{tabular}

with > 4-mm MPD dilation, as confirmed by prior imaging (computed tomography or magnetic resonance imaging), and EUSPD had been attempted in them because ERCP failed or could not be performed. Conversely, patients who had a non-dilated duct associated with pancreatic atrophy, neoplastic pancreatic strictures, or for whom anticoagulants could not be discontinued were excluded.

As shown in > Table 1, information was collected on the following patient characteristics: age, sex, active smoking and alcohol consumption, cause of MPD dilation, etiology of CP or cause of cephalic pancreatic duodenectomy (CDP), pain and associated analgesic consumption. Data on morphological characteristics, such as weight and body mass index, and on 

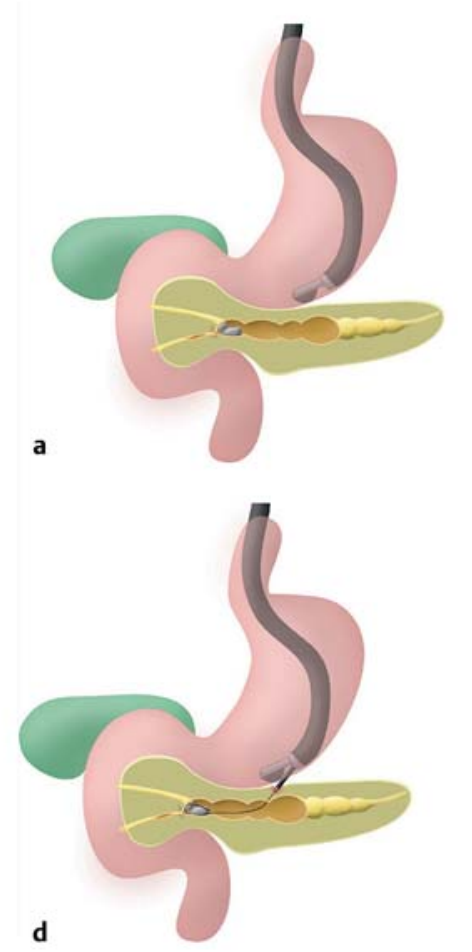
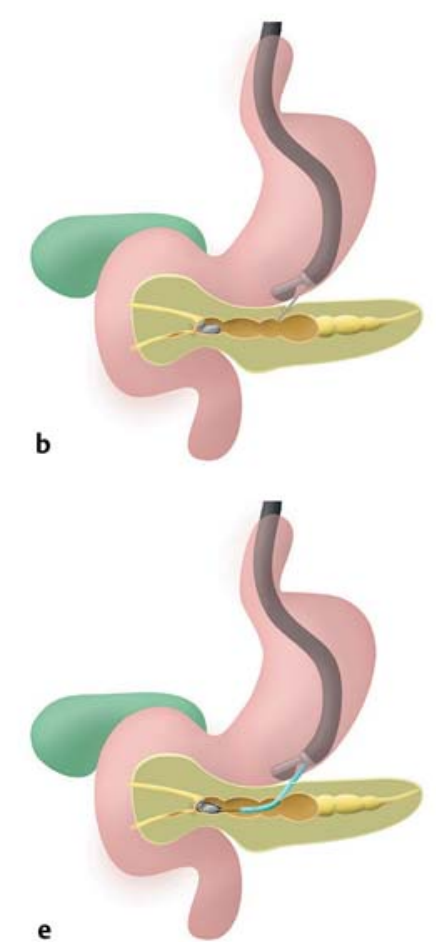
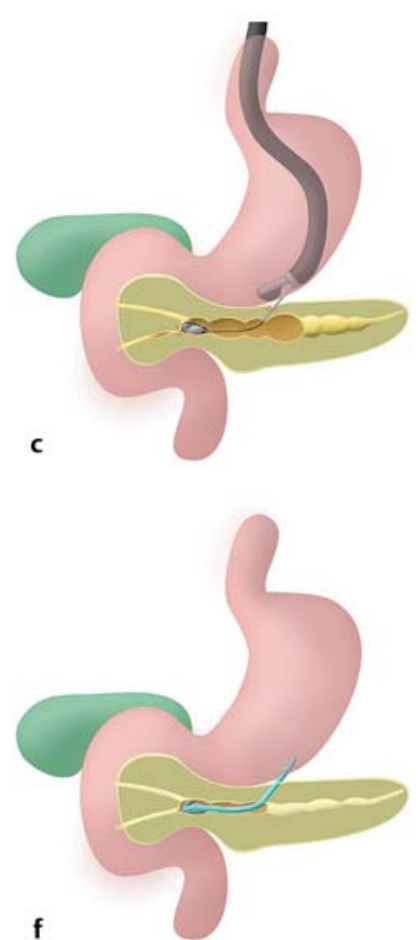

- Fig. 1 Diagram of the different stages of EUS-guided Wirsungo-gastrostomy. a Expansion of the main pancreatic duct (MPD) $>4 \mathrm{~mm}$. $\mathbf{b}$ Echoguided puncture with a 19G needle, opacification of the MPD. c Placement of a guidewire in the MPD. $\mathbf{d}$ Using a 6Fr cystotome set in pure section, a pancreatic-gastric fistula is created. e Installation of a straight transgastric pancreatic plastic prosthesis. $\mathbf{f}$ End of the procedure. (Source: Oscar Siame)

duration of hospitalization and early complications also were collected.

\section{Endoscopic procedure}

The procedure was performed by interventional endoscopists who were experts in ERCP and in therapeutic EUS. All patients received general anesthesia and were intubated and placed in the supine position. Post-procedural acute pancreatitis prophylaxis with nonsteroidal anti-inflammatory drugs was administered, as recommended in European Society of Gastrointestinal Endoscopy guidelines [29]. The endoscope used was always a linear therapeutic EUS-scope with at least a 3.6-mm operating channel (Pentax or Fujifilm, Japan), with fluoroscopic control.

Pancreatico-gastrostomy was performed following as described here ( $\mathbf{F i g . 1}$ and $>$ Fig. 2). Step 1: Puncture of dilated MPD under EUS using a 19G fine needle aspiration needle (EchoTip, Cook Endoscopy, United States or Boston Scientific, United States). A pancreatography was then performed by injecting diluted contrast into the MPD. Step 2: Placement in the main pancreatic duct of a 0.035 -inch guidewire under fluoroscopic control (Jag-Wire, Boston Scientific, United States). Step 3: Creation of a pancreatic-gastric fistula using a 6Fr cystotome (Cysto Gastro, Endoflex, Voerde, Germany), with application of a pure section current (120 Watts, Erbe Vio, Erlangen, Germany) to cross the gastric wall and the pancreatic parenchyma. Step 4: Placement over the wire of a 7Fr straight plastic stent between the MPD and the stomach. In patients without CDP, when the guidewire crossed the stenosis and was in the duodenum, the appointment technique was performed at a later time.

The endoscopic data ( $\vee$ Table 2 ) collected were on the maximum diameter of the MPD evaluated by EUS, the location and type of stenosis, the type of equipment used (puncture needle, cystotome, guide wire, stent), and any intraoperative complications, such as digestive bleeding, acute pancreatitis, or pain.

\section{Postoperative and long-term follow-up}

The patients fasted for 24 hours after the procedure and were discharged after 3 to 5 days. They were either seen in a clinic or at the hospital at 3 and 6 months, and every 6 months thereafter, or contacted by phone if they were living too far away (patients referred from other centers). A standard questionnaire ( $>$ Fig. 3 ) was used to assess their pain, weight variation, development of diabetes or exocrine insufficiency, and quality of life.

More specifically, pain was systematically documented before and during follow-up, using a visual analogic scale (VAS) from 0 to 10 . The improvement was classified into three categories: "Complete regression" if a patient had no residual pain (VAS =0); "partial regression" if patient had occasional and lowintensity pain episodes (VAS $\leq 3$ ) with a reduction of at least three points compared to the VAS collected before the proce- 

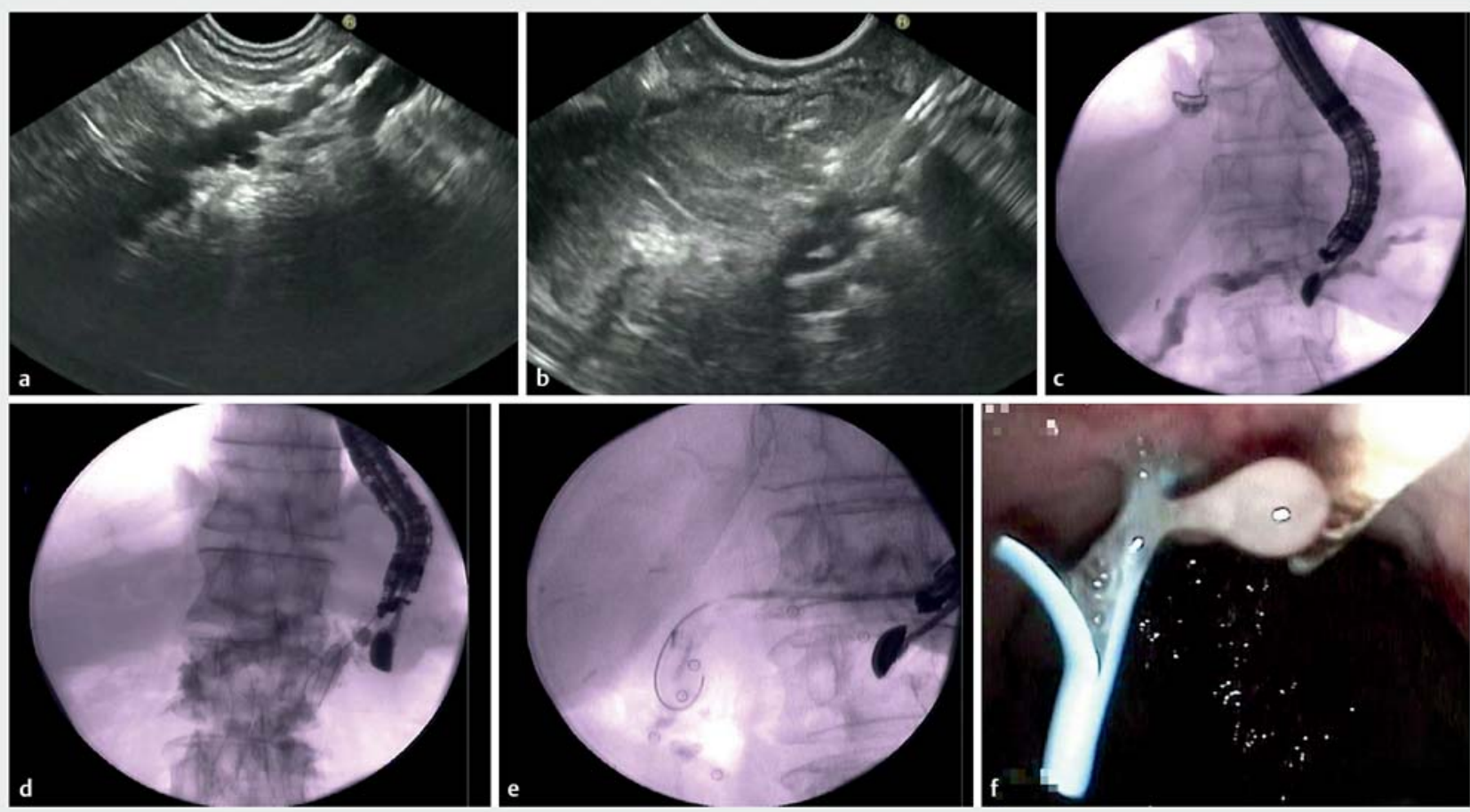

> Fig. 2 The different stages of Wirsungo-gastrostomy under echo endoscopy. a Expansion of the main pancreatic duct (MPD > 4 mm). $\mathbf{b}$ Echoguided puncture using a 19G needle. c Opacification of the MPD under fluoroscopic control. $\mathbf{d}$ Installation in the MPD of a wire. e Creation of a pancreatic-gastric fistula using a 6Fr cystotome and then installation of a straight transgastric pancreatic plastic prosthesis. $\mathbf{f}$ Endoscopic view, resulting from pancreatic sugar at the end of the procedure.

Table 2 Endoscopic data.

\begin{tabular}{|c|c|}
\hline & Global $n=27$ \\
\hline \multicolumn{2}{|l|}{ Type of stenosis, \% (n) } \\
\hline - Fibrous & $33.3 \%(9)$ \\
\hline - Calculation & $33.3 \%(9)$ \\
\hline - Anastomotic & $33.3 \%(9)$ \\
\hline \multicolumn{2}{|l|}{ Cause of ERCP failure, \% (n) } \\
\hline - Inaccessible papilla & $33.3 \%(9)$ \\
\hline - Obstructive lithiasis & $33.3 \%(9)$ \\
\hline - Impassable stenosis of the MPD & $33.3 \%(9)$ \\
\hline \multicolumn{2}{|l|}{ Location of stenosis, \% (n) } \\
\hline - Cephalic & $44.4 \%(12)$ \\
\hline - Isthmic & $22.2 \%(6)$ \\
\hline - Anastomotic & $33.3 \%(9)$ \\
\hline Previous ERCP, \% (n) & $66.6 \%(18)$ \\
\hline Average MPD dilatation mm, [min-max] & $6.5[3-12]$ \\
\hline
\end{tabular}

dure; and finally, "no regression" if there were no significant changes despite constant consumption of palliate II or III analgesics over time, according to the World Health Organization classification.

Delayed AEs, including early recurrence, EUS-PD stent migration, and digestive perforation were reported, as well as the need for subsequent surgery in case of complete failure.

\section{Objectives}

The main objective was to evaluate the technical success of EUS-PD in patients with symptomatic dilation of the MPD in whom ERCP had failed or it could not be performed. Success was defined as placement of a plastic stent between the stomach and the MPD.

The secondary objectives were to document the safety profile with the complication rate for the procedure, the clinical success in terms of pain regression, and patient quality of life as measured on the standard follow-up questionnaire, and to define a standardized management algorithm.

\section{Statistical analysis}

The File Maker Pro (Apple Inc., United States) and Axigate databases of the APHM (Axigate SAS, Paris, France) were used to collect the data. Statistical analyses were conducted with SPSS statistics software (IBM Rochester, Minnesota, United States). The data were expressed as means with extremes and percentages. Frequencies and percentages were used for the qualitative 


Follow-up survey
Follow-up after WG-EUS
Pain

- Current pain (EVA 0 à 10/10)

- Evolution of pain since the WG-EUS:

a. EVA scale

b. Change in analgesic consumption

c. Morphine withdrawal o rreduction of interdose

- Pain following ambulatory changes

- Pain before scheduled changes

\section{Weight/Appetite}

- Weight variation sinceWG-EUS

- Change in appetite

\section{Quality of life}

- Improved quality of life

- Frequency of change

Fig. 3 Follow-up survey.

variables. Medians and means were used for the quantitative variables. A univariate subgroup analysis was performed and $P<0.05$ was considered statistically significant.

\section{Results}

\section{Patient characteristics}

Twenty-seven patients ( $70.4 \%$ male, average age $61 \pm 12$ years) were included in the analysis between January 2010 and January 2019. Nine patients had altered anatomy after surgery; the other 18 patients had CP without prior pancreatic resection. The etiology of CP and the indications for MPD in patients in the group with altered anatomy are detailed in $>$ Table 1 .

The indication for drainage was dilation of the MPD associated with presence of painful pancreatic symptomatology in all patients. Of these, $60 \%$ of patients had recurrent acute pancreatitis attacks; the remaining $40 \%$ had radiating postprandial pain (typical pancreatic pain).

The causes of previous ERCP failure were inaccessibility to the papilla in nine patients, obstructive lithiasis in nine patients, and fibrous stenosis impassable by the guidewire in nine patients ( $>$ Table 2 ).

\section{Endoscopic procedure}

Technical success

Technical success was achieved in $92.5 \%$ of patients $(n=25)$

( $\triangleright$ Table 3 ). Access to the MPD was possible in $100 \%$ of patients by the transgastric route. The plastic stent was placed in an anterograde transgastric fashion in $88 \%$ of patients $(n=24)$ and in a transpapillary retrograde fashion after use of the "ren- dezvous" technique in one patient (4\%). In two patients, the Wirsungo-gastric stent placement failed. In the two cases of stent placement failure, cyanoacrylate (mixed with lipiodol) was injected into the puncture path associated with the closure of the transgastric access with clips (Instinct, Cook, United States), without clinical consequences.

Of the placed stents, $92.5 \%(n=25)$ were $7 \mathrm{Fr}$ plastic stents $(7 \mathrm{~cm}$ or $5 \mathrm{~cm})$, whereas only one patient had a fully-covered metal stent placed.

\section{Complications}

There were no intraoperative complications. The overall rate of postoperative AEs was $22 \%(n=6)$. Four patients (14\%) experienced postoperative non-specific pain, with spontaneous improvement. The mean length of hospitalization after the EUSPD was 4.2 days [2-8]. In case of complications, the hospitalization stay was extended. Two cases of delayed benign acute edematous pancreatitis (7\%) were reported (on Days 20 and 30 after stent placement), both requiring a 72-hour hospitalization, with no further intervention required.

During a mean 34.2-month follow-up, five spontaneous stent migrations occurred. Four were discovered fortuitously during the follow-up endoscopy, planned for stent exchange ( 3 plastic and 1 metal). Of them, one patient still had pain and one was found based on recurrence of abdominal pain (confirmed by imaging) in a patient in whom EUS-PD had previously provided relief. A stent was replaced along the Wirsungo-gastric path in these two patients, whereas the asymptomatic patients remained stent-free.

\section{Clinical success and factors}

Clinical success was achieved in $88.8 \%$ of patients $(n=24)$ ( Table 3). Half of them described a "complete regression" and half a "partial regression." Oppositely, $11.2 \%$ of patients did not show any symptomatic improvement. A subgroup analysis revealed that $100 \%$ of patients in the altered anatomy group were improved, compared to $83 \%$ in the CP group.

Improved quality of life was reported in $74 \%$ of patients and a change in appetite in $66.6 \%$. Univariate analysis ( $>$ Table 4 ) revealed a significant difference with regard to the consumption of class I painkillers, weight variation, and improvement in quality of life in favor of the altered anatomy group compared with the CP patients $(P<0.05$; Table 3$)$.

\section{Evolution during follow-up}

Median follow-up was 34.2 months ( minimum 4 months maximum 108 months), with $92.6 \%$ of patients $(n=25)$ having more than 12 months of follow-up. The mean stent exchange interval was 5 months (4 to 6 months) and the mean number of stent changes during follow-up was 3.7 (1 to10). At the last reassessment, 22 patients still had a plastic stent in place, exchanged every 6 months.

Moreover, during the whole follow-up, no patient underwent secondary surgery or celiac plexus block under ultrasound endoscopy due to persistent pain. Two patients died during the follow-up, one from digestive bleeding secondary to portal hy- 
- Table 3 Technical modalities and patient follow-up after endoscopic treatment.

\begin{tabular}{|c|c|c|c|}
\hline & $\begin{array}{l}\text { Global } \\
n=27\end{array}$ & $\begin{array}{l}\text { Altered anatomy } \\
\mathrm{n}=\mathbf{9}\end{array}$ & $\begin{array}{l}\text { PCC } \\
n=18\end{array}$ \\
\hline Technical success, \% (n) & $92.5 \%(25)$ & $88.8 \%(8)$ & $94.4 \%(17)$ \\
\hline Clinical success ${ }^{1} \%(n)$ & $88.8 \%(24)$ & $88.8 \%(8)$ & $83 \%(15)$ \\
\hline \multicolumn{4}{|l|}{ Pain regression, \% (n) } \\
\hline - Complete & $44.4 \%(12)$ & $77.8 \%(7)$ & $27.8 \%(5)$ \\
\hline - Partial & $44.4 \%(12)$ & $22.2 \%(2)$ & $55.5 \%(10)$ \\
\hline - Absent & $11.2 \%(3)$ & $0 \%(0)$ & $16.7 \%(3)$ \\
\hline \multicolumn{4}{|l|}{ Other clinical symptoms, \% (n) } \\
\hline - Decreased acute pancreatic attacks & $88.8 \%(24)$ & $100 \%(9)$ & $83 \%(15)$ \\
\hline - Improving the quality of life & $74 \%(20)$ & $100 \%(9)$ & $61 \%(11)$ \\
\hline - Modification of appetite & $66.6 \%(18)$ & $88.8 \%(8)$ & $55.5 \%(10)$ \\
\hline \multicolumn{4}{|l|}{ Complications, \% (n) } \\
\hline - Acute pancreatitis & $7 \%(2)$ & $11 \%(1)$ & $5.5 \%(1)$ \\
\hline - Postoperative pain & $14 \%(4)$ & $11 \%(1)$ & $16.6 \%(3)$ \\
\hline - Death & 0 & 0 & 0 \\
\hline \multicolumn{4}{|l|}{ Endoscopic procedure, medium, [min-max] } \\
\hline - Average length of hospital stay, in days & $4.2[2-8]$ & $4.1[3-6]$ & $4.3[2-8]$ \\
\hline - Interval of stent exchange, in months & $5[4-6]$ & $6[6-6]$ & $5[4-6]$ \\
\hline - Number of stent exchanges & $3.7[1-10]$ & $4.8[1-10]$ & $3.2[1-7]$ \\
\hline Median follow-up, \% (month) & $34.2[41-02]$ & $44.8[16-102]$ & $28.9[4-81]$ \\
\hline
\end{tabular}

- Table4 Varied uni-analysis of the associated factors according to the cause of the obstruction.

\begin{tabular}{|c|c|c|c|}
\hline & $\begin{array}{l}\text { Altered anatomy } \\
\mathrm{N}=9\end{array}$ & $\begin{array}{l}\text { PCC } \\
N=18\end{array}$ & $P$ value \\
\hline Consumption of Level 1 analgesics, \% (n) & $0 \%(0)$ & $50 \%(9)$ & 0.017 \\
\hline Weight change, \% (n) & $88.8 \%(8)$ & $38 \%(7)$ & 0.014 \\
\hline Improvement in quality of life, \% (n) & $100 \%(9)$ & $61 \%(11)$ & 0.030 \\
\hline
\end{tabular}

pertension and one from septic shock, in both cases unrelated to the EUS-PD procedures.

\section{Discussion}

Symptomatic MPD dilation, CP or altered anatomy-related, due to ductal hyper-pressure, is the target of endoscopic and historically, surgical treatment. In the event that ERCP fails or cannot be performed, even after extracorporeal shockwave lithotripsy, resection surgery was the only option. The latter is based on the realization of a pancreatic-jejunal or pancreatic-gastric anastomosis [14]. Two types of interventions were described: decompressive surgery or Frey intervention in case of dilated MPD without inflammatory mass, and resection surgery or Whipple intervention when there is an inflammatory or suspicious mass, consisting of cephalic duodeno-pancreatectomy (CDP). Despite a good efficacy rate $[15,30]$ morbidity reaches $30 \%$ and mortality $2 \%$ [16-18], still with a risk of anastomotic stricture $[20,30]$.

For this reason and following the development of therapeutic EUS, EUS-PD was proposed by François et al. in 2002 [12] as an alternative to surgery for of symptomatic MPD dilation. The literature since then ( $\downarrow$ Table 5 ) documents a technical success rate of $86 \%$, according to a recent review, with a complication 
- Table 5 Summary of the various studies of EUS-PD.

\begin{tabular}{|c|c|c|c|c|c|c|}
\hline Authors & No. of patients & $\begin{array}{l}\text { Technical } \\
\text { success }\end{array}$ & Clinical success & Complications & $\begin{array}{l}\text { Overall follow- } \\
\text { up in months }\end{array}$ & Type of stent \\
\hline $\begin{array}{l}\text { Francois } \\
\text { GIE, } 2002\end{array}$ & 4 & $100 \%$ & $75 \%$ & $0 \%$ & 12 & Plastic \\
\hline $\begin{array}{l}\text { Teissier } \\
\text { GIE, } 2007\end{array}$ & 36 & $92 \%$ & $69 \%$ & $14 \%$ & 14.5 & Plastic \\
\hline $\begin{array}{l}\text { Kahaleh } \\
\text { GIE, } 2007\end{array}$ & 13 & $92 \%$ & $77 \%$ & $16 \%$ & 14 & Plastic \\
\hline $\begin{array}{l}\text { Brauer } \\
\text { GIE, } 2009\end{array}$ & 8 & $88 \%$ & $50 \%$ & $0 \%$ & 14 & Plastic \\
\hline $\begin{array}{l}\text { Barkey } \\
\text { GIE, } 2010\end{array}$ & 21 & $48 \%$ & 1 & $2 \%$ & 13 & Plastic \\
\hline $\begin{array}{l}\text { Ergun } \\
\text { Endoscopy, } 2011\end{array}$ & 20 & $90 \%$ & $72 \%$ & $19 \%$ & 37 & Plastic \\
\hline $\begin{array}{l}\text { Fujii } \\
\text { GIE, } 2013\end{array}$ & 45 & $74 \%$ & $83 \%$ & $6 \%$ & 32 & Plastic \\
\hline $\begin{array}{l}\text { Will } \\
\text { WJG, } 2015\end{array}$ & 94 & $88 \%$ & $72 \%$ & $15 \%$ & 28 & Plastic and metal \\
\hline $\begin{array}{l}\text { Tyberg } \\
\text { GIE, } 2017\end{array}$ & 80 & $89 \%$ & $81 \%$ & $20 \%$ & 24 & Plastic \\
\hline $\begin{array}{l}\text { Oh } \\
\text { GIE, } 2017\end{array}$ & 25 & $100 \%$ & $100 \%$ & $20 \%$ & 18.5 & Metal \\
\hline
\end{tabular}

rate between $0 \%$ and $20 \%$, and a clinical success rate between $50 \%$ and $100 \%$ [31-34]. Our study is consistent with this literature, since the technical success rate was $92.5 \%$, $92.6 \%$ of patients had a decrease in painful attacks during long-term follow-up, and $88.9 \%$ had "complete" or "partial" regression of pain after a median follow-up of almost 3 years. In addition, no severe AEs or procedural mortality were reported.

Focusing on patients with altered anatomy after cephalic duodenopancreatectomy (or Whipple resection), a recent international multicenter study compared enteroscopic endoscopic retrograde pancreatography (e-ERP) and EUS-PD. A total of 66 patients and 75 interventions were identified (40 EUS-PD versus 35 e-ERP). Rates of technical and clinical success were $92.5 \%$ and $87.5 \%$, respectively, in the EUS-PD group compared with $20 \%$ and $23 \%$ in the e-ERP group [35]. We found similar results in our study, with $100 \%$ of symptoms relieved.

Technically, a minimum MPD dilatation $\geq 4 \mathrm{~mm}$ is required to safely perform the EUS-guided puncture. However, Umar Hayat et al [36] showed that puncture of an undilated pancreatic duct is technically feasible, although difficult. In his study, he showed that it can be done by using a small-caliber guidewire, $4 \mathrm{~F}$ angioplasty balloon, and reverse $3 \mathrm{~F}$ single pigtail stents. If there was no dilation, we did not attempt the drainage because of the uncertainty of effectiveness. Celiac block can be proposed in such a case, as previously published.

Second, the type of stent to use is another matter, given that the majority of teams use plastic. Indeed, migration or obstruc- tion requiring endoscopic reintervention occurs frequently, with a delay before obstruction of around 120 days. Few centers recommend placement of several plastic stents after ERCP to extend the time without dysfunction and shorten the calibration period [37]. However, when performing Wirsungo-gastrostomy, it is neither reasonable nor useful to place multiple stents, since the purpose is not to calibrate an impassable stricture, but to remove the ductal hyper-pressure. When multiple stents are preferable, dual $3 \mathrm{Fr}$ stents may provide a permanent wick to keep the fistula open, as described in a small series [36]. Also, this would significantly increase the risk of procedural failure and complications by leaving an active pancreatic fistula after the cystotome was passed. More recently, Oh et al [38] reported the use of a fully-covered self-expanding metal stent when performing EUS-PD. The technical and clinical success rates were $100 \%$ in 25 patients with symptomatic dilation of the main canal with prior ERCP failure. Nevertheless, $20 \%$ of early AEs with acute abdominal pain have been reported, probably due to poor tolerance. In addition, the permeability time was 126.9 days during the mean follow-up (221.1 days), which is no different than with plastic stents [39].

The final technical aspect is the approach. Although unstable, the transgastric approach remains the most used because it allows direct access to the MPD. A recent study proposed trans-bulbar access, arguing that the endoscope stability in the bulb is superior [39]. The technical success rate was sim- 


\section{MPD stenosis}

Failure or impossibility of ERCP

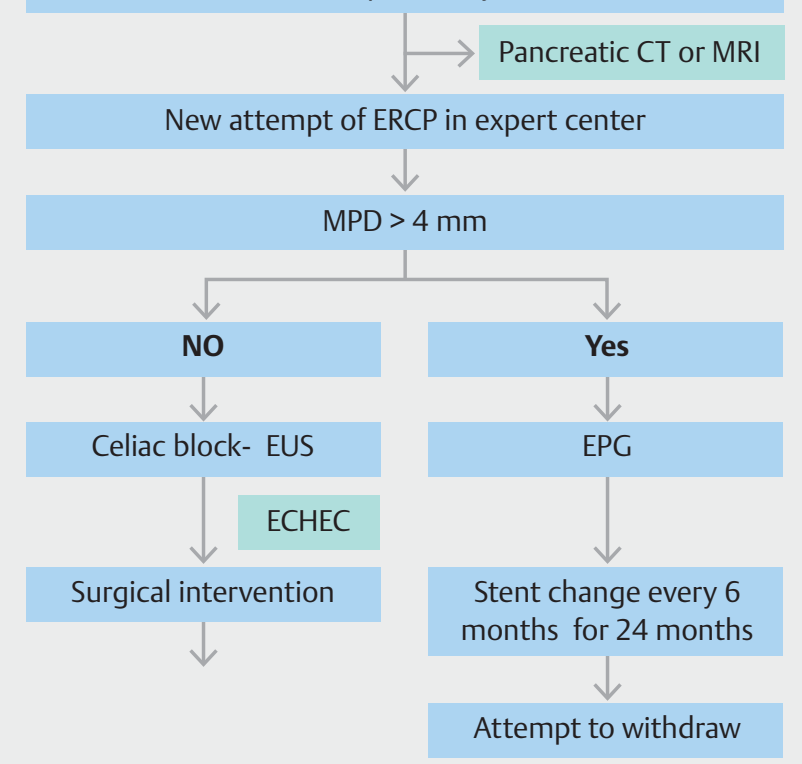

- Fig. 4 Management algorithm in case of failure of ERCP or in ability to perform it. MPD, main pancreatic duct; ERCP, endoscopic retrograde cholangiopancreatography; EUS, endoscopic ultrasonography; EUS-PD, EUS-guided pancreatic duct drainage

ilar, but in cases of isthmic or corporal stenosis or altered digestive anatomy, the trans-bulbar pathway is not feasible.

To date there is no standardized scheme for the interval between changes and the time required to obtain calibration. In our study, the average stent replacement time was 5.4 months. We propose a management algorithm that suggests changing the stent every 6 months for 24 months, then attempting to remove it ( $\vee$ Fig. 4). The fact that in the absence of a stent, EUSPD may persist over time because of a fibrosis phenomenon seems interesting. In five patients, we did not observe pain recurrence after spontaneous stent migration and without new placement. Therefore, there are two hypotheses: (1) After migration of the stents, the anastomosis remains functional; and (2) The natural progression of the disease towards atrophy of the pancreatic parenchyma results in a decrease in the neuropathic component of pain. This phenomenon was described in the study by Tyberg et al [28] of two cases of pancreatic-gastric fistula that remained functional after stent removal, which were detected with secretin MRI.

There is still a lack of prospective data on which to base a recommendation for wider use of this technique, which should be reserved for tertiary centers experienced with therapeutic EUS procedures. In 2018, however, the European Society of Gastrointestinal Endoscopy (ESGE) published recommendations [29] for using EUS-PD as a bridge to surgery in patients with insoluble pain, in whom surgery was contraindicated, or for whom surgery represented a significant risk. We believe that rather than bridging the gap to surgery, EUS-PD should be a substitute for ductal decompression surgery, and that in patients suspected of having resectable malignant lesions, only surgical resection should be performed.

\section{Conclusion}

In conclusion, this study demonstrated that EUS-PD is safe, minimally invasive, and effective in the management of symptomatic MPD dilation after ERCP has failed or cannot be performed. This technique should be done in expert centers, but it is an alternative to duct decompression surgery. Technical and device advancements will continue to improve the safety and efficiency of this procedure. Prospective studies are needed to confirm its place in the therapeutic strategy for MPD dilation.

\section{Competing interests}

The authors declare that they have no conflict of interest.

\section{References}

[1] Lévy P, Domínguez-Muñoz E, Imrie C et al. Epidemiology of chronic pancreatitis: burden of the disease and consequences. United Eur Gastroenterol ] 2014; 2: 345-354

[2] Mullady DK, Yadav D, Amann ST et al. Type of pain, pain-associated complications, quality of life, disability and resource utilisation in chronic pancreatitis: a prospective cohort study. Gut 2011; 60: 77-84

[3] Ebbehøj N, Borly L, Bülow J et al. Pancreatic tissue fluid pressure in chronic pancreatitis relation to pain, morphology, and function. Scand J Gastroenterol 1990; 25: 1046-1051

[4] Olesen SS, Bouwense SAW, Wilder-Smith OHG et al. Pregabalin reduces pain in patients with chronic pancreatitis in a randomized, controlled trial. Gastroenterology 2011; 141: 536-543

[5] Wilder-Smith CH, Hill L, Osler W et al. Effect of tramadol and morphine on pain and gastrointestinal motor function in patients with chronic pancreatitis. Dig Dis Sci 1999; 44: 1107-1116

[6] Cremer M, Devière J, Delhaye $M$ et al. Stenting in severe chronic pancreatitis: results of medium-term follow-up in seventy-six patients. Endoscopy 1991; 23: 171-176

[7] Cremer M, Deviere J, Delhaye M et al. Non-surgical management of severe chronic pancreatitis. Scand J Gastroenterol Suppl 1990; 175: $77-84$

[8] Dumonceau J-M, Deviere J, Moine OL et al. Endoscopic pancreatic drainage in chronic pancreatitis associated with ductal stones: longterm results. Gastrointest Endosc 1996; 43: 547-555

[9] Brauer BC, Chen YK, Fukami N et al. Single-operator EUS-guided cholangiopancreatography for difficult pancreaticobiliary access (with video). Gastrointest Endosc 2009; 70: 471-479

[10] Widmer ], Sharaiha RZ, Kahaleh M. Endoscopic ultrasonographyguided drainage of the pancreatic duct. Gastrointest Endosc Clin N Am 2013; 23: 847-861

[11] Tessier G, Bories E, Arvanitakis M et al. EUS-guided pancreatogastrostomy and pancreatobulbostomy for the treatment of pain in patients with pancreatic ductal dilatation inaccessible for transpapillary endoscopic therapy. Gastrointest Endosc 2007; 65: 233-241 
[12] François E, Kahaleh M, Giovannini M et al. EUS-guided pancreaticogastrostomy. Gastrointest Endosc 2002; 56: 128-133

[13] Fink AS, de Ayala VP, Chapman M et al. Radiologic pitfalls in endoscopic retrograde pancreatography: pancreas. 1986; 1: 180-187

[14] Cahen DL, Rauws EAJ, Busch OR et al. Endoscopic versus surgical drainage of the pancreatic duct in chronic pancreatitis. N Engl J Med 2007; 356: 676-684

[15] Lucas CE, McIntosh B, Paley D et al. Surgical decompression of ductal obstruction in patients with chronic pancreatitis. Surgery 1999; 126 : 790-795

[16] Adams DB, Ford MC, Anderson MC. Outcome after lateral pancreaticojejunostomy for chronic pancreatitis. Ann Surg 1994; 219: 481-489

[17] Nealon WH, Thompson JC. Progressive loss of pancreatic function in chronic pancreatitis is delayed by main pancreatic duct decompression a longitudinal prospective analysis of the modified Puestow procedure. Ann Surg 1993; 217: 458-468

[18] Markowitz JS, Rattner DW, Warshaw AL. Failure of symptomatic relief after pancreaticojejunal decompression for chronic pancreatitis. Strategies for salvage. Arch Surg 1994; 129: 374-379; discussion 379-380

[19] Reid-Lombardo KM, Ramos-De la Medina A, Thomsen K et al. Longterm Anastomotic Complications After Pancreaticoduodenectomy for Benign Diseases. J Gastrointest Surg 2007; 11: 1704-1711

[20] Amano H, Takada T, Ammori B] et al. Pancreatic duct patency after pancreaticogastrostomy: long-term follow-up study. Hepatogastroenterology 1998; 45: 2382-2387

[21] Bories E, Pesenti C, Caillol F et al. Transgastric endoscopic ultrasonography-guided biliary drainage: results of a pilot study. Endoscopy 2007; 39: 287-291

[22] Park DH, Jeong SU, Lee BU et al. Prospective evaluation of a treatment algorithm with enhanced guidewire manipulation protocol for EUSguided biliary drainage after failed ERCP (with video). Gastrointest Endosc 2013; 78: 91-101

[23] Barkay O, Sherman S, McHenry L et al. Therapeutic EUS-assisted endoscopic retrograde pancreatography after failed pancreatic duct cannulation at ERCP. Gastrointest Endosc 2010; 71: 1166-1173

[24] Fujii LL, Topazian MD, Abu Dayyeh BK et al. EUS-guided pancreatic duct intervention: outcomes of a single tertiary-care referral center experience. Gastrointest Endosc 2013; 78: 854-864.e1

[25] Mallery S, Matlock J, Freeman ML. EUS-guided rendezvous drainage of obstructed biliary and pancreatic ducts: report of 6 cases. Gastrointest Endosc 2004; 59: 100-107
[26] Will U, Fueldner F, Thieme A-K et al. Transgastric pancreatography and EUS-guided drainage of the pancreatic duct. J Hepatobiliary Pancreat Surg 2007; 14: 377-382

[27] Kahaleh M, Hernandez A], Tokar J et al. EUS-guided pancreaticogastrostomy: analysis of its efficacy to drain inaccessible pancreatic ducts. Gastrointest Endosc 2007; 65: 224-230

[28] Tyberg A, Sharaiha RZ, Kedia P et al. EUS-guided pancreatic drainage for pancreatic strictures after failed ERCP: a multicenter international collaborative study. Gastrointest Endosc 2017; 85: 164-169

[29] Dumonceau J-M, Delhaye M, Tringali A et al. Endoscopic treatment of chronic pancreatitis: European Society of Gastrointestinal Endoscopy (ESGE) Guideline - Updated August 2018. Endoscopy 2019; 51: 179193

[30] Jiang L, Ning D, Cheng $Q$ et al. Endoscopic versus surgical drainage treatment of calcific chronic pancreatitis. Int J Surg 2018; 54: 242247

[31] Rösch T, Daniel S, Scholz M et al. Endoscopic treatment of chronic pancreatitis: a multicenter study of 1000 patients with long-term follow-up. Endoscopy 2002; 34: 765-771

[32] Delhaye M, Arvanitakis M, Verset G et al. Long-term clinical outcome after endoscopic pancreatic ductal drainage for patients with painful chronic pancreatitis. Clin Gastroenterol Hepatol 2004; 2: 1096-1106

[33] Ponchon T, Bory RM, Hedelius F et al. Endoscopic stenting for pain relief in chronic pancreatitis: Results of a standardized protocol. Gastrointest Endosc 1995; 42: 452-456

[34] Fujii-Lau LL, Levy MJ. Endoscopic ultrasound-guided pancreatic duct drainage. J Hepatobiliary Pancreat Sci 2015; 22: 51-57

[35] Chen YI, Levy MJ, Moreels TG et al. An international multicenter study comparing EUS-guided pancreatic duct drainage with enteroscopyassisted endoscopic retrograde pancreatography after Whipple surgery. Gastrointest Endosc 2017; 85: 170-177

[36] Hayat U, Freeman ML, Trikudanathan G et al. Endoscopic ultrasoundguided pancreatic duct intervention and pancreaticogastrostomy using a novel cross-platform technique with small-caliber devices. Endosc Int Open 2020; 8: E196-E202

[37] Costamagna G, Bulajic M, Tringali A et al. Multiple stenting of refractory pancreatic duct strictures in severe chronic pancreatitis: longterm results. Endoscopy 2006; 38: 254-259

[38] Oh D, Park DH, Cho MK et al. Feasibility and safety of a fully covered self-expandable metal stent with antimigration properties for EUSguided pancreatic duct drainage: early and midterm outcomes (with video). Gastrointest Endosc 2016; 83: 366-373.e2

[39] Giovannini M. Endoscopic ultrasound-guided pancreatic duct drainage: Ready for the prime time? Endosc Ultrasound 2017; 6: 281 